American Journal of Applied Sciences 6 (5): 897-901, 2009

ISSN 1546-9239

(C) 2009 Science Publications

\title{
Risk Factors for Wound Complications Following Abdominoplasty
}

\author{
Samir K. Jabaiti \\ Department of Plastic and Reconstructive surgery, Jordan University Hospital, \\ P.O. Box 13046, Amman, Jordan
}

\begin{abstract}
Problem Statement: Abdominoplasty has become an increasingly popular procedure. Risk factors affecting wound complications of abdominoplasty are not adequately defined in literature. Identification of these risk factors is crucial for better patient's selection and counseling. The objectives of this study were to determine wound complication rate following abdominoplasty and to examine the relationship of a set of possible risk factors with the incidence of complications. Approach: We studied 116 patients (107 women and 9 men) who underwent abdominoplasty at Jordan University Hospital, between June 1997 and June 2007. Data were collected from patients' medical records and analyzed to determine types and rates of surgical wound complications. Fourteen possible risk factors were investigated using logistic regression analysis to evaluate their relationship with the occurrence of wound complications. Risk factors examined were: age, sex, body mass index, parity number, smoking history, history of diabetes mellitus, previous gastroplasty for morbid obesity, previous abdominal surgical scars, type of abdominoplasty, plication of recti, hernia repair, operative time and operative blood loss. Results: A total of 29 patients (two males and 27 females) (25\%) had wound complications. The most common complication was seroma. It was encountered in 15 cases $(12.9 \%)$. Six patients $(5.2 \%)$ had wound infection. Partial skin necrosis was encountered in four cases $(3.4 \%)$. Two patients $(1.7 \%)$ developed wound dehiscence and two patients $(1.7 \%)$ had hematoma. The only factors significantly increased the complication rate were: increased body mass index $(\mathrm{p}=$ $0.002)$ and history of smoking $(\mathrm{p}=0.004)$. Conclusions and Recommendations: This study confirms the adverse effect of overweight and cigarette smoking on the incidence of wound complication rate following abdominoplasty. We recommend that overweight patients and smokers undergoing abdominoplasty should be adequately counseled and informed about the increased risks. In addition, prophylactic measures should be properly taken to decrease wound complication rate in these groups of patients.
\end{abstract}

Key words: Abdominoplasty, wound complications, risk factors, smoking, obesity

\section{INTRODUCTION}

In the last few decades, abdominoplasty has become an increasingly popular and satisfying method of body contouring ${ }^{[1-8]}$. Factors that may have contributed to the popularity of abdominoplasty include: the society's emphasis on youthful appearance, increased awareness of self-image and fitness and the growth of aesthetic surgery in general ${ }^{[1]}$. The usual candidates for abdominoplasty are women in their fourth through sixth decades, which had completed their families and left with lax abdominal wall, striae of pregnancy, or scars of previous surgical operations ${ }^{[1,9]}$. Another group of patients seeking for abdominoplasty among other body contouring procedures are those patients who had successful gastric bypass surgery with massive weight reduction. These patients are left with redundant skin, so abdominoplasty aims to improve post-weight reduction body aesthetics and function ${ }^{[2,9-}$ 11].

Although many investigators have reported on the complications of abdominoplasty ${ }^{[2-20]}$, the risk factors associated with post abdominoplasty wound complications were not adequately addressed in the literature. Identification of these risk factors is considered a crucial issue for surgeons who perform abdominoplasty. It would help them in accurate patient selection and counseling. In addition, they may consider adopting prophylactic measures against proven risk factors.

In this retrospective study we report our experience with 116 consecutive cases of abdominoplasty procedures. The objectives of the study are to report the incidence of post-abdominoplasty wound complications and to assess the influence of different possible risk factors on incidence of these wound complications.

Corresponding Author: Samir K. Jabaiti, Department of Plastic and Reconstructive surgery, Jordan University Hospital,P.O. Box 13046, Amman, Jordan 


\section{MATERIALS AND METHODS}

Patients: This study has been approved by the IRB (Institutional Review Board) and the Jordan University Hospital Ethical Committee. Between June 1997 and June 2007, a total of 116 patients had undergone abdominoplasty procedures at Jordan University Hospital, Amman, Jordan. Medical records of patients were available for review and data was collected and analyzed to determine the post operative wound complications rate and to examine the effect of different possible risk factors on the incidence of wound complication.

Collected data included: Age, sex, Body Mass Index (BMI ), parity number, smoking history, medical history, previous gastroplasty for morbid obesity, previous upper and lower abdominal scars and the presence of abdominal wall hernias. Operative data included the type of abdominoplasty (lower transverse abdominal "W" abdominoplasty vs. inverted "T" abdominoplasty), plication of recti, hernial repair, operative time and estimated intra-operative blood loss. BMI was calculated at the time of surgery.

Surgical technique: All abdominoplasty procedures were performed by the same plastic Surgeon (the author). Pre-operatively, patients were assessed regarding abdominal wall skin and musculoapponeurotic laxity by the grasping technique. Patients were examined for the presence of ventral abdominal hernias. Surgical incisions were marked in the standing position. Surgical procedures were performed under general inhalational anesthesia.

Prophylactically, patients received 5000 IU of subcutaneous heparin (three times daily) until they were fully ambulated. In 79 patients, lower abdominal "W" incision was used. The upper flap was raised to the extent of the sternal and costal margins, the excess skin and subcutaneous adipose tissues were excised and the fatty layer deep to the superficial fascia was sharply excised. The umbilicus was preserved and brought through a hole created in the upper abdominal flap. In cases of large umbilical hernias, the umbilicus was sacrificed and a neo-umbilicus was created. Diastasis of the recti, when present, was corrected by plication of the rectus fascia from the xiphoid process till the pubis using Nylon loop No 1. After meticulous hemostasis, the wound was closed in two dermal layers using 3-0 polyglactin 910 suture material. Two closed suction drains were left in the sub-cutaneous space and were removed when the amount of drained fluid was less than $30 \mathrm{~mL}$ per $24 \mathrm{~h}$ (within 4-8 days). In 37 patients with severe abdominal redundancy and midline tissue excess, an inverted " $T$ " incision (Fleur-de-lys abdominoplasty) was used. In this group of patients the planned tissue excess was resected with minimal undermining of the flaps. None of the patients had liposuction.

Statistical analysis: Statistical analysis was carried out using the SPSS version 16.0 (SPSS, Chicago, IL., USA). Logistic regression analysis was used to correlate patients age, sex, parity, BMI, smoking history, diabetes mellitus, previous gastroplasty for morbid obesity, presence of upper and lower abdominal scars, type of abdominoplasty, plication of recti, accompanied hernial repair, intra-operative blood loss and operative time to the incidence of wound complications. P-value of less than 0.05 was considered statistically significant.

\section{RESULTS}

Table 1 summarizes patients and operative data. There was 107 females (92.2\%) and 9 males (7.8\%). The mean age of the patients was 40.8 years (range 1775 ). The mean parity number was 4.1 (range $0-15$ ). Twenty one patients $(18.1 \%)$ gave history of smoking. Twelve patients (10.3\%) were diabetic and 26 patients (22.4\%) had previous vertical banded gastroplasty for morbid obesity. Regarding previous abdominal scars, twelve patients $(10.3 \%)$ had right subcostal scars and 42 patients (36.2\%) had lower abdominal scars. Seventy nine patients $(68.1 \%)$ had lower abdominal "W" type abdominoplasty, while 37 patients (31.9\%) underwent inverted " $T$ " type abdominoplasty.

\begin{tabular}{lr} 
Table 1: Demographic and operative data \\
\hline Criteria \\
\hline Age in years; mean (range) \\
Sex & $40.8(17-75)$ \\
$\quad$ Male & 9 \\
Female & 107 \\
BMI; mean (range) & $29.6(21.0-48.4)$ \\
Parity number; mean (range) & $4.1(0-15)$ \\
Smoking history; no (\%) & $21(18.1 \%)$ \\
History of diabetes mellitus; no (\%) & $12(10.3 \%)$ \\
Previous gastric partition; no ( \%) & $26(22.4 \%)$ \\
Right subcostal scar; no( \%) & $12(10.3 \%)$ \\
Lower abdominal scar; no ( \%) & $42(36.2 \%)$ \\
Type of abdominoplasty & \\
$\quad$ Inverted "T" Plasty; no ( \%) & $37(31.9 \%)$ \\
$\quad$ "W" Plasty; no (\%) & $79(68.1)$ \\
Plication of recti; no (\%) & $46(39.7 \%)$ \\
Hernial repair; no ( \%) & $33(28.4 \%)$ \\
Operative blood loss (mls); mean (range) & $328(150-750)$ \\
Operative time (minutes); mean (range) & $112(60-210)$ \\
\hline
\end{tabular}


Am. J. Applied Sci., 6 (5): 897-901, 2009

Table 2: Wound complications

\begin{tabular}{lc}
\hline Complication & No. $(\%)$ \\
\hline Seroma & $15(12.9 \%)$ \\
Wound infection & $6(5.2 \%)$ \\
Partial skin necrosis & $4(3.4 \%)$ \\
Hematoma & $2(1.7 \%)$ \\
Wound dehiscence & $2(1.7 \%)$ \\
Total & $29(25 \%)$ \\
\hline
\end{tabular}

Table 3: Factors affecting wound complication rate

\begin{tabular}{ll}
\hline Factor & $\mathrm{p}$ value \\
\hline Age & 0.605 \\
Sex & 0.815 \\
Body mass index (BMI) & $0.002^{*}$ \\
Parity number & 0.423 \\
Smoking history & $0.004^{*}$ \\
Diabetes mellitus & 0.175 \\
Gastric bypass surgery & 0.863 \\
Sub-costal scars & 0.690 \\
Lower abdominal scars & 0.548 \\
Type of abdominoplasty incision & 0.449 \\
Plication of recti & 0.790 \\
Hernial repair & 0.819 \\
Estimated intra-operative blood loss & 0.405 \\
Estimated operative time & 0.750 \\
\hline *statistically significant value &
\end{tabular}

There were no deaths or major life threatening complications in this series. Table 2 summarizes types of wound complications encountered. A total of 29 patients $(25 \%)$ developed wound complications. The most common complication was seroma. It was encountered in 15 cases (12.9\%). Six patients $(5.2 \%)$ had wound infection; they were treated by intra-venous antibiotics and wound drainage.Partial skin necrosis was encountered in four cases (3.4\%); all of them healed by secondary intention with repeated dressings in the out patient clinic. Two patients $(1.7 \%)$ developed wound dehiscence. In one patient, it was minor and healed within 2 weeks. The second patient had dehiscence of nearly one third of the length of the abdominoplasty incision. It took her two months to heal with a residual wide scar that required revision surgery. Two patients (1.7\%) had hematoma that required evacuation under general anesthesia.

When the complications were correlated to the 14 possible risk factors by logistic regression analysis, the only factors that significantly increased the complication rate were increasing $(\mathrm{BMI})(\mathrm{p}=0.002)$ and history of cigarette smoking $(\mathrm{p}=0.004)$. Table 3 shows the results of statistical analysis with $\mathrm{P}$ values.

\section{DISCUSSION}

The first major report about the incidence of complications following abdominoplasty was published by Grazer and Goldwyn ${ }^{[13]}$. In their survey of 10,490 abdominoplasties performed by 958 surgeons, the complications were: wound infection (7.8\%), hematoma (6\%) and wound dehiscence (5.4\%). Deep vein thrombosis was reported in $1.1 \%$ and pulmonary embolism in $0.8 \%$. The mortality rate in that survey was reported as $0.02 \%$. Nevertheless, no effort in that study was made to correlate the incidence of different complications with possible risk factors.

In the present study, the wound complication rate $(25 \%)$ was consistent with the results of recent studies on the incidence of post abdominoplasty wound complication rates of $11-32 \%{ }^{[4,16]}$. Seroma was found to be the most common complication in our series. It occurred in 15 patients (12.9\%). The incidence of seroma following abdominoplasty is variable and ranging from $1-26 \%{ }^{[18,21]}$.

Present study showed that overweight at the time of surgery as measured by increasing BMI, was a significant risk factor for increasing wound complication rate following abdominoplasty. Vastine $e t$ $a l .{ }^{[2]}$ found in a review of 90 abdominoplasties that $80 \%$ of obese patients had complications compared with the borderline and non-obese patients $(33$ and $32.5 \%$ respectively ${ }^{[2]}$. Hester et $a l^{[15]}$ studied 563 abdominoplasty procedures and found that obesity was the single factor in predicting major morbidity ${ }^{[15]}$. This adverse effect of overweight was also reported by others $^{[3,8]}$. Two studies, however, failed to prove an association between increasing BMI and wound complications $^{[16,17]}$.

It has been documented by clinical and experimental studies that cigarette smoking has adverse effects on wound healing and surgical results of different surgical procedures ${ }^{[22-27]}$. Our findings of positive effect of cigarette smoking on wound complications following abdominoplasty were consistent with the results of others ${ }^{[4,11,12,20]}$.

The effect of patient's gender on post abdominoplasty wound complications was studied by Van Uchelen et al. ${ }^{[3]}$ who reviewed 86 cases of abdominoplasty (14 men and 72 women), they found that wound morbidity was significantly greater in male patients $(64.3 \%)$ compared to female patients $(15.3 \%)^{[3]}$. In present study there was no correlation between patient's sex and the incidence of wound complications.

Our result of negative correlation between diabetes mellitus and wound complications contradicts the results of Hensel et al. ${ }^{[4]}$ who found in a review of 190 abdominoplasty patients that history of diabetes and/or hypertension increased the complication rate ${ }^{[4]}$. This may be explained by the relatively small percentage of diabetic patients in present study. 
Present study did not show a significant positive effect of increasing parity number on wound complication rate. The influence of parity number on post abdominoplasty wound complications has not been addressed in the literature. This finding may be significant in communities where multiparty is common.

Recently, following successful gastric bypass surgery for morbid obesity, patients are left with massive redundant skin. Many of these patients seek body contouring procedures including abdominoplasty. Similar to previous reports, no correlation was found between previous gastric bypass surgery and increased risk of wound complications ${ }^{[2,8-10]}$.

Present study did not show a significant correlation between the type of abdominoplasty and increased risk of wound complications. These results contradict the finding of Chaouat et al. ${ }^{[14]}$ who reported in their study of 258 patients a significant increase in skin necrosis in the inverted " $T$ " plasty group ${ }^{[14]}$. A similar finding was reported by Dillerud ${ }^{[18]}$. In inverted "T" plasty, wound healing problems occur mainly at the junction of the branches of the " $T$ " where three flaps meet ${ }^{[14]}$. Being aware of this potential risk, we performed the inverted " $T$ " plasty with minimal undermining of the flaps to allow tension free closure.

We did not find a correlation between previous abdominal surgical scars and wound complications. The safety of abdominoplasty on previously scarred abdomen was confirmed by El-khatib and Bener who successfully performed 76 abdominoplasties on previously scarred abdomen including 25 subcostal scars ${ }^{[7]}$ Rieger et al. ${ }^{[19]}$ performed successful complete abdominoplasty in two patients with bilateral subcostal scars by selectively dissecting and preserving one to three periumibilical abdominal wall perforator vessels to secure flap blood supply ${ }^{[19]}$ This result may be explained by our conservative approach in dissection in this group of patients we limited the undermining of the upper flaps especially on the side of the scar. In addition, we were cautious to preserve as much as possible of the musculocutaneous perforators.

\section{CONCLUSION}

In conclusion, present study confirms the adverse effect of overweight and cigarette smoking on the incidence of wound complication rate following abdominoplasty. Overweight patients and smokers who are undergoing abdominoplasty should be adequately counseled and informed about the increased risks. In addition, prophylactic measures should be properly taken to decrease wound complication rate in these groups of patients. We recommend further prospective studies to examine potential risk factors to provide the surgeon with accurate solid data for better patient's counseling and selection.

\section{ACKNOWLEDGEMENT}

The author would to thank Dr Hamdi Abu Ali, senior surgical resident, Jordan University Hospital. Amman-Jordan for his assistance in carrying out the statistical analysis and Dr Zuhair Bani Ismail, Associate professor, Faculty of Veterinary Medicine, Jordan University of Science and Technology for his help in reviewing the manuscript.

\section{REFERENCES}

1. Matarasso, A., 1989. Abdominolipoplasty. Clin. Plast. $\quad$ Surg., $\quad 16$ : 289-303. http://www.ncbi.nlm.nih.gov/pubmed/2661108?do $\mathrm{pt}=$ Abstract.

2. Vastine, V.L., R.F. Morgan, G.S. Williams, T.J. Gampper, D.B. Drake, L.K. Knox and K.Y. Lin, 1999. Wound complications of abdominoplasty in obese patients. Ann. Plast. Surg., 42: 34-39. http://www.ncbi.nlm.nih.gov/ pubmed/9972715.

3. van Uchelen, J.H., P.M. Werker and M. Kon, 2001. Complications of abdominoplasty in 86 patients. Plast. Reconst. Surg., 107: 1869-1873. http://www. ncbi.nlm.nih.gov/pubmed/11391211.

4. Hensel, J.M., J.A. Lehman Jr, M.P. Tantri, M.G. Parker, D.S. Wagner and N.S. Tophan, 2001. An outcomes analysis and satisfaction survey of 199 consecutive abdominoplasties. Ann. Plast. Surg., 46: 357-363. http://www.ncbi.nlm.nih.gov/ pubmed/11324875.

5. Floros, C. and P.K. Davis, 1991. Complications and long-term results following abdominoplasty: A retrospective study. Br. J. Plast. Surg., 44: 190-194. DOI: 10.1016/0007-1226(91)90125-4.

6. Baxter, R.A., 2001. Controlled results with abdominoplasty. Aesth. Plast. Surg., 25: 357-364. Abdominoplasty following gasrointestinal bypass surgery. Plast. Reconst. Surg., 25: 357-364. http://dx.DOI.org/10.1007/s00266-001-0010-1.

7. El-Khatib, H.A., and A. Bener, 2004. Abdominal dermolipectomy in an abdomen with pre-existing scars: A different concept. Plast. Reconstr. Surg., 114: 992-997. http://www.ncbi.nlm.nih.gov/ pubmed/15468409.

8. Duff, C.G., S. Aslam and R.W. Griffiths, 2003. Fleur-de-Lys abdominoplasty- a consecutive case series. Br. J. Plast. Surg., 56: 557-566. DOI: 10.1016/S0007-1226(03)00174-7. 
9. Savage, R.C., 1983. 500-509.

http://www.ncbi.nlm.nih.gov/ pubmed/6828584.

10. Soundararajan, V., N.B. Hart and C.M. Royston, 1995. Abdominoplasty following vertical banded gastroplasty for morbid obesity. Br. J. Plast. Surg., 48: 423-427. DOI: $10.1016 / \mathrm{S} 0007-$ 1226(95)90254-6.

11. Gravante, G., A. Araco, R. Sorge, F. Araco, D. Delogu and V. Cervelli, 2007. Wound infections in post-bariatric patients undergoing body contouring abdominoplasty: The role of smoking. Obes. Surg., 17: 1325-1331. DOI: 10.1007/s11695007-9236-6.

12. Manassa, E.H., C.H. Hertl and R.R. Olbrisch, 2003. Wound healing problems in smokers and nonsmokers after 132 abdominoplasties. Plast. Reconstr. Surg., 111: 2082-2087. http://www.ncbi. nlm.nih.gov/pubmed/12711974.

13. Grazer, F.M. and R.M. Goldwyn, 1977. Abdominoplasty assessed by survey with emphasis on complications. Plast. Reconst. Surg., 59: 513517. http://www.ncbi.nlm.nih.gov/pubmed/847027.

14. Chaouat, M., P. Levan, B. Lalanne, T. Buisson, P. Nicolau and M. Mimoun, 2000. Abdominal dermolipectomies: Early postoperative complications and long-term unfavorable results. Plast. Reconst. Surg., 106: 1614-1618. http://www.ncbi.nlm.nih.gov/pubmed/11129195.

15. Hester, T.R. Jr., W. Baird, J. Bostwick, F. Nahai and J. Cukic, 1989. Abdominoplasty combined with other major surgical procedures: Safe or sorry? Plast. Reconstr. Surg., 83: 997-1004. http://www.ncbi.nlm.nih.gov/pubmed/2524854.

16. Sozer, S.O., F.J. Agullo, A.A. Santillan and C. Wolf, 2007. Decision making in abdominoplasty. Aesthetic. Plast. Surg., 31: 117127. DOI: $10.1007 / \mathrm{s} 00266-006-0148-y$.

17. Stewart, K.J., D.A. Stewart, B. Coghlan, D.H. Harrison, B.M. Jones and N. Waterhouse, 2006. Complications of 278 consecutive abdominoplasties. J. Plast. Reconstr. Aesthet. Surg., 59: 1152-1155. DOI: 10.1016/j.bjps.2005. 12.060 .

18. Dillerud, E., 1990. Abdominoplasty combined with suction lipoplasty: A study of complications, revisions, and risk factors in 487 cases. Ann. Plast. Surg., 25: 333-343. http://www.ncbi.nlm.nih. gov/pubmed/2147821.
19. Rieger, U.M., M. Aschwanden, D. Schmid, D.F. Kalbermatten, G. Pierer and M. Haug, 2007. Perforator-sparing abdominoplasty technique in the presence of bilateral subcostal scars after gastric bypass. Obes. Surg., 17: 63-67. DOI: 10.1007/s11695-007-9007-4.

20. Rogliani, M., L. Labardi, E. Silvi, F. Maggiulli, M. Grimaldi and V. Cervelli, 2006. Smokers: Risks and complications in abdominal dermolipectomy. Aesthetic. Plast. Surg., 30: 422424. DOI: $10.1007 / \mathrm{s} 00266-006-0010-2$.

21. Khan, U.D., 2008. Risk of seroma with simultaneous liposuction and abdominoplasty and the role of progressive tension sutures. Aesthetic. Plast. Surg., 32: 93-99. DOI: 10.1007/s00266-0079004-y.

22. Gravante, G., A. Araco, R. Sorge, R. Caruso, F. Araco, F. Nicoli, D. Delogu and V. Cervelli, 2008. Postoperative wound infections after breast reductions: The role of smoking and the amount of tissue removed. Aesthetic. Plast. Surg., 32: 25-31. DOI: 10.1007/s00266-007-9048-z.

23. Møller, A.M., N. Villebro, T. Pedersen and H. Tønnesen, 2002. Effect of preoperative smoking intervention on postoperative complications: A randomised clinical trial. Lancet, 359: 114-117. http://www.ncbi.nlm.nih.gov/pubmed/11809253.

24. Akoz, T., M. Akan and S. Yildirim, 2002. If you continue to smoke, we may have a problem: Smoking's effects on plastic surgery. Aesthetic. Plast. Surg., 26: 477-482. DOI: 10.1007/s00266002-2045-3.

25. Krueger, J.K. and R.J. Rohrich, 2001. Clearing the smoke: The scientific rationale for tobacco abstention with plastic surgery. Plast. Reconstr. Surg., 108: 1063-1073. http://www.ncbi.nlm.nih. gov/pubmed/11547174.

26. Chang, L.D., G. Buncke, S. Slezak and H.J. Buncke, 1996. Cigarette smoking, plastic surgery and microsurgery. J. Reconstr. Microsurg., 12: 467-474. http://www.ncbi.nlm.nih.gov/ pubmed/8905547.

27. Rejali, M., A.R. Rejali, L. Zhang and S. Yang, 2005. Effects of nicotine on the cardiovascular system. Vasc. Dis. Prev., 2: 135-144. DOI: 10.2174/1567270053507246. 